\title{
Imaging an E-future: Education as a Process Towards Understanding
}

\author{
Margaret E. Robertson
}

\begin{abstract}
Education is the vital tool for understanding the complexities of living within social structures-regardless of scale. Traditions that shaped the infrastructure of ancient communities leave a residue presence today in architectural, cultural, economic and political values and practices. The past helps us comprehend the rapid changes to the space, place and environment interactions associated with transport and communications developments. Nowadays time-space compression is reorganising our global networks and commodity flows. Understanding events in the twenty-first century requires communities to adjust but preserve their collective memory.
\end{abstract}

Keywords Ways of knowing - Education - Understanding - Ecological change • Memory preservation

\section{Towards Understanding}

New geographies are products of time and space reorganisation. The history of human occupancy on earth highlights periods of great change caused by migration, trade and colonisation of lands distant from 'home'. These periods facilitated the spread of ideas and cultural, economic and political practices. At the heart of much of the interaction has been trade. Hence, colonisation, imperialism (mostly of European origins), capitalism associated with the free market economy, and the production of monetary wealth, are key processes for understanding global transactions. The argument we make is that whilst new technologies enable transactions by anyone, anywhere, anyplace and across traditional boundaries, the processes that

M.E. Robertson $(\square)$

La Trobe University, Melbourne, Australia

e-mail: m.robertson@latrobe.edu.au

(C) The Author(s) 2016

M.E. Robertson (ed.), Communicating, Networking: Interacting,

SpringerBriefs in Global Understanding, DOI 10.1007/978-3-319-45471-9_8 
underpin each transaction-small and large - are similar. However, this assumes the universality of the European and United States superpower discourse (Said 1994). In Said's words:

\begin{abstract}
Without significant exception the universalizing discourses of modern Europe and the United States assume the silence, willing or otherwise, of the non-European world. There is incorporation, there is inclusion; there is direct rule; there is coercion. But there is only infrequently an acknowledgement that the colonised people should be heard from, their ideas known. (Said 1994, p. 50)
\end{abstract}

Understanding processes that lead to 'native nationalism' (Said 1994, p. 51), will undoubtedly, help explain contemporary geo-political discourses. And, whilst emergence from colonial rule by modern nation-states is a field of scholarship beyond the scope of this book we do acknowledge the powers of contemporary communications process helping to shape local communities and give voice to their cultural needs. In this book, case studies from Sierra Leone and Papua-New Guinea provide illustrations of innovative practices bringing about change and improving lives within local communities. Worthy of celebration for showing how new technologies can help transform local health, education and daily survival, they also highlight the dangers of assumptions reliant on centralised managerialism, without adequate consultation and capacity building at local levels. Two-way education helps to maintain traditions and cultural identity within a framework that can benefit from modern infrastructure and preserve the 'landscape memory' (see Schama 1995; Lowenthal 2015).

Whilst this may be good advice, finding 'voice' to negotiate better futures remains a struggle for many indigenous societies. Help is not necessarily derived from central agencies. However, being connected to the worlds of others via the internet can provide agency to expand upon traditional knowledge, and ideally, evolve into contemporary lifestyles in harmony with neighbours - near and far. Regrettably, the time-space compression affordances of new technologies are not all for the good of humanity. Internet tools can, and are, fuelling contemporary crises of faith. The age appears to have encouraged defection from mainstream values and the privileging of subjective politics where 'wrong' can appear to outweigh social good. In this sense there is a politicization of the ideals of democracy for personal gain (Žižek 1999). As Keen (2015) asserts in his book titled The Internet is not the answer the surveillance capacity of big data services such as Facebook and Instagram are "creating a panopticon of information gathering" (p. xiv) which: "Rather than focussing in renaissance, it has created a self-centered culture of voyeurism and narcissism" (ibid.).

Why? Arguably, the pace of information flows made possible with new technologies has overwhelmed the political processes. The conditions for knowledge transfer have changed and in turn systems have to change to accommodate new spatial and temporal realities. Transdiscipline approaches are needed, and perhaps, as David Harvey concedes in his most recent book (2016) we need to consider a 'critical anti-capitalist' world. Neo-liberalism and capitalist agendas may be both the high and low points of the Anthropocene. 
Along with the continual making of new geographies, including the concretization of the landscape as human populations increasingly live in mega-cities, the draw down on survival physical resources is also threatening the environment. Nature and culture intertwined are elemental concepts for human survival. Climate change is real. Warming of our oceans and air currents is directly linked to the symbols of modern living - car ownership, long-distance travel, larger homes containing multiple energy using appliances, and perhaps of greatest impact for families - access to lines of monetary credit. Critical theorists and scholars like Harvey (2016) are now raising the alarm for agencies to consider almost the unthinkable for future survival. A right hand turn from capitalism may help save the planet but any slowing of the market driven juggernaut will require education of the current millennial generation. What follows is a summary analysis of some practices which use new learning tools whilst simultaneously encouraging responsible lifestyle choices.

\section{Everyday Knowing and Education in the Millennial Age}

Migration shifts to big cities and concentrations of people into even bigger cities is reshaping our urban traditions and further depleting the rural landscapes of labour. Farm workers and their traditions are being reshaped by technologies with labour force reduction being a significant outcome. Whilst labour force depletion in agricultural pursuits is set to continue ${ }^{1}$ the need for workers to build infrastructure in new and expanding cities - most notably in East Asia-offers diverse opportunities for alternative employment. For instance, in its Urban Development Series, the World Bank Group (2015) surveys of urban 'spatial growth' in East Asia shows how big data, geospatial technologies and visual imagery are helping the urbanisation transition process. This intersection of technology helps to improve everyday lives in rural areas and contributes to better outcomes in the construction and reconstruction of urban spaces. Knowledge dissemination in the technically connected age also helps transfer skills on how to make improvements that reduce carbon footprint and foster new ecologies for living based on principles of sustainability. Urban gardens, and learning how to garden, are skills for everyday living which can be learnt through community based programs and action based learning in schools. Rather than being lost from memory and identity smart technologies can help younger generations adapt the skills of their rural forebears into current food production lifestyles suitable for urban survival.

Signs of what is shaping up to be a self-help way of living are already operating in the global economy. Uber, AirBnB, online personal and food shopping, are global systems changing the ways in which people interact with one another and

\footnotetext{
${ }^{1}$ See The World Bank prediction that 'Today's urban population of about 3.5 billion people is projected to reach 5 billion by 2030 , with two-thirds of the global population living in cities.' Retrieved June, 2016 from http://www.worldbank.org/en/topic/urbandevelopment.
} 
their respective communities. These are all signs on an increasing independence within populations and willingness to reach beyond the mainstream systems. Entrepreneurial in their respective ways each system is creating new economies and shifting the balance of consumer interactions. This can be disruptive for business being conducted in traditional ways and already there as signs of regulatory frameworks appearing from governments reacting to community lobby groups including local taxi companies and hotel chains. In the contemporary age of mobility and growth across real space hegemonic power displacement is a likely casualty. Personal geographies operating in juxtaposition with traditional values and day to day operating systems can be viewed as fracturing the orderly conduct of community life. Uncertainty in government or slow responses to community driven disruption can have negative and positive implications. Where personal or group initiatives go against the accepted societal norms the collective memory of the people can be threatened. Optimistic thinking offers an alternative. Innovation and creative use of the tools of the age can transform lives and help tackle poverty, abuse and unemployment. The imperative for education is to encourage and support leaders who are charismatic in style but guided by humanitarian principles and social justice outcomes.

\section{Final Recommendations}

The passage of time inevitability shapes place and space connections. They change constantly. Just as history helps us to understand the dynamics of people and place interactions collective memory is useful but not an exhaustive bowl of wisdom. Different paradigms or discourses operate simultaneously and understanding the processes at work within localised communities is complex. Social dissent, hybrid cultures, mobility and environmental stress are all sources of community upheaval. In the current anthropogenic period, with the right decisions, any of these dynamics can precipitate an evolution in lifestyles to harmonious outcomes between nature and culture (Foucault 1994; Whitehead 1971). The alternatives of disunity and chaos are also possible. The pace of change and the opportunities to connect people and place through digital networks is an energy source like no other in history. Education imaginaries that reflect the digital age are the major defence humanity has for better futures. At the same time structures are needed for daily life to operate efficiently. No matter the scale — global, national, regional and local—shared value systems are imperatives for education.

In the International Year of Global Understanding the challenge for education is to capture the views of the majority perspectives and be inclusive of minority voices. The struggle for global understanding will require monumental effort from within and outside mainstream organisations including governments, corporate and small scale enterprises. This is not simply a matter for the millennial generation alone. 
Open Access This chapter is distributed under the terms of the Creative Commons Attribution 4.0 International License (http://creativecommons.org/licenses/by/4.0/), which permits use, duplication, adaptation, distribution and reproduction in any medium or format, as long as you give appropriate credit to the original author(s) and the source, provide a link to the Creative Commons license and indicate if changes were made.

The images or other third party material in this chapter are included in the work's Creative Commons license, unless indicated otherwise in the credit line; if such material is not included in the work's Creative Commons license and the respective action is not permitted by statutory regulation, users will need to obtain permission from the license holder to duplicate, adapt or reproduce the material.

\section{References}

Foucault, M. 1994. The order of things. An anthropology of the human sciences. New York: Vintage Books.

Harvey, D. 2016. The ways of the world. London: Profile Books.

Keen, A. 2015. The internet is not the answer. London: Atlantic Books.

Lowenthal, D. 2015. The past is a foreign country - revisited. Cambridge: Cambridge University Press.

Said, E. W. 1994. Culture and imperialism. New York: Vintage Books.

Schama, S. 1995. Landscape and memory. New York: Vintage Books.

Whitehead, A.N. 1971. Concept of nature. London: Cambridge University Press.

World Bank Group. 2015. East Asia's Changing Urban Landscape : Measuring a Decade of Spatial Growth. Urban Development; Washington, DC: World Bank. Online at https:// openknowledge.worldbank.org/handle/10986/21159 License: CC BY 3.0 IGO.”vvv

Žižek, S. 1999. The ticklisk subject. The absent centre of political ontology. London: Verso. 